\title{
Cardiovascular medication burden in dementia disorders: a nationwide study of 19,743 dementia patients in the Swedish Dementia Registry
}

\author{
Pavla Cermakova ${ }^{1,2^{*}}$, Seyed-Mohammad Fereshtehnejad ${ }^{3}$, Kristina Johnell ${ }^{4}$, Bengt Winblad ${ }^{1,5}$, \\ Maria Eriksdotter ${ }^{3,5}$ and Dorota Religa ${ }^{1,5}$
}

An erratum has been published for this article. Available here: http://alzres.com/content/6/8/63

\begin{abstract}
Introduction: Administration of several cardiovascular drugs has an effect on dementia. We aimed to investigate whether there are differences in the use of cardiovascular medication between different dementia disorders.

Methods: We obtained information about dementia patients from the Swedish Dementia Registry. Patients were diagnosed with one of these dementia disorders: Alzheimer's disease $(n=8,139)$, mixed dementia $(n=5,203)$, vascular dementia $(n=4,982)$, Lewy body dementia $(n=605)$, frontotemporal dementia $(n=409)$ and Parkinson's disease dementia $(n=405)$. Multivariate logistic regression analysis was performed to investigate the association between use of cardiovascular medication and dementia disorders, after adjustment for age, gender, living alone, cognitive status and total number of drugs (a proxy for overall co-morbidity).
\end{abstract}

Results: Seventy percent of all the dementia patients used cardiovascular medication. Use of cardiovascular drugs is common in patients with vascular and mixed dementia. Male gender, higher age, slightly better cognitive status and living with another person was associated with use of cardiovascular medication.

Conclusions: Cardiovascular medication is used extensively across dementia disorders and particularly in vascular and mixed dementia. Future research should investigate the tolerability and effectiveness of these drugs in the different dementia disorders.

\section{Introduction}

Dementia is a devastating disease that is highly related to age. Several cardiovascular $(\mathrm{CV})$ disorders have been suggested as risk factors for dementia, such as hypertension [1], hypercholesterolemia [2,3], atrial fibrillation [4] and heart failure [5]. Correct management of these conditions can slow down cognitive decline [6], reduce the risk for dementia [7] and maintain stability in patients with dementia [8]. Several CV drugs have been reported to decrease the risk of developing dementia [7,9], to improve cognition [10-12] or - on the contrary - to impair

\footnotetext{
* Correspondence: Pavla.Cermakova@ki.se

'Department of Neurobiology, Care Sciences and Society, Center for Alzheimer Research, Division for Neurogeriatrics, Karolinska Institutet, 14157 Huddinge, Sweden

${ }^{2}$ International Clinical Research Center and St.Anne's University Hospital, Pekařská 53, 65691 Brno, Czech Republic

Full list of author information is available at the end of the article
}

cognition [13], independent from the effect of treating CV diseases.

Treatment with antihypertensive medication was associated with a $50 \%$ reduction of dementia risk in the trial Systolic Hypertension in Europe [14]. On the other hand, The Study on Cognition and Prognosis in the Elderly did not find any positive impact of antihypertensive treatment on cognitive decline and dementia [15]. Antagonists of the renin-angiotensin-aldosterone system, such as angiotensin-converting enzyme inhibitors and angiotensin II receptor blockers, have recently gained interest in the dementia field, because the reninangiotensin-aldosterone system is involved in several major processes such as regulation of cerebral blood flow, inflammation or memory consolidation [16-18]. Centrally active angiotensin-converting enzyme inhibitors have been shown to protect against brain injury and to slow down cognitive decline [6,19-21]. Angiotensin II 
receptor blockers have been associated with a significant reduction in the incidence and progression of dementia compared with other $\mathrm{CV}$ drugs in a prospective cohort analysis [22]. Clinical trials aimed to investigate the impact of lipid-lowering drugs on dementia have not been able to show a significant benefit on the reduction of dementia risk [23].

Alzheimer's disease (AD) is the most prevalent dementia disorder and accounts for about two-thirds of dementia cases [24]. The second most common type is vascular dementia $(\mathrm{VaD})$. Individuals with $\mathrm{AD}$ are often afflicted with $\mathrm{VaD}$, which is then named mixed dementia (MixD) [25]. There is a lack of reliable epidemiological data on the prevalence of dementia with Lewy bodies (DLB), but this is considered the third most common type [26,27]. DLB often overlaps with Parkinson's disease dementia (PDD) [28]. Frontotemporal dementia (FTD) accounts for about 4 to $10 \%$ of all dementia subtypes [24].

AD patients used to be considered as the healthiest group of dementia patients [29], since it has been reported that $\mathrm{AD}$ is associated with fewer comorbidities compared with the other dementia subtypes [30,31]. These results are not in line with more recent papers that have reported the opposite $[32,33]$. In a study by Imfeld and colleagues, however, $\mathrm{CV}$ comorbidities and exposure to $\mathrm{CV}$ drugs were significantly lower in $A D$ patients, whereas the opposite result was found in $\mathrm{VaD}$ patients [29]. A recent study on incident $\mathrm{AD}$ cases showed that $34 \%$ were treated with more than five drugs [34].

The treatment of CV diseases or administration of $\mathrm{CV}$ drugs may be negatively influenced by several conditions associated with dementia. Autonomic dysfunction is present in all dementia disorders [35,36], particularly in DLB and PDD [37], and complicates the management of blood pressure. Furthermore, dysphagia in AD patients [38], living alone [39] and a high level of cognitive impairment [40] can cause problems with the administration of drugs.

There is an insufficient number of studies on comparisons between all different dementia disorders $[41,42]$, probably due to the lack of large patient material. This study aims to investigate whether there are differences in the use of $\mathrm{CV}$ medication between different dementia disorders in a large population of dementia patients from the Swedish Dementia Registry (SveDem). To our knowledge, SveDem includes the highest number of patients with different dementia disorders worldwide.

\section{Methods}

\section{Study population}

We analyzed cross-sectional data from SveDem, which is a national registry for improvement of the quality of diagnostic workup, treatment and care of patients with dementia in Sweden. This registry included 28,722 patients who were newly diagnosed with dementia either at a memory clinic or in a primary care unit from 2007 to 2012. Age, gender, demographic data, body mass index, Mini Mental State Examination (MMSE) scores, diagnostic procedures, type of dementia disorder and treatment are recorded in this web-based registry.

Since 2009 SveDem has been monitored to ensure the quality of the registered data. According to a recent annual report, $76 \%$ of memory clinics are now under monitoring [43]. Ten percent of the registrations at each unit are randomly selected and checked with the data in the medical records to see whether the data correspond.

\section{Definitions}

Dementia was diagnosed according to the International Classification of Diseases version 10 [44]. In addition, DLB was diagnosed based on the McKeith criteria [28] and the Manchester criteria were used for the diagnosis of FTD [45]. Unspecified dementia is diagnosed if the dementia etiology is unknown or if investigations aimed to differentiate the type of dementia have not been performed. Other dementia types comprise rare dementia disorders that are represented, for example, by corticobasal degeneration or alcoholic dementia. The following dementia disorders are included in SveDem: AD, VaD, MixD, LBD, FTD, PDD, unspecified dementia and other types.

In SveDem, the following classes of drugs were registered at the beginning of the diagnostic workup with the possible answers 'yes'/'no'/'do not know': CV drugs, cholinesterase inhibitors (ChEI), $N$-methyl-D-aspartate (NMDA) receptor antagonists, antidepressants, anxiolytics, antipsychotics and hypnotics/sedatives. The total number of prescribed drugs was also recorded. The latter variable was used as a proxy for overall comorbidity [46]. CV drugs comprised antihypertensives, anticoagulants, lipid-lowering drugs, antidiabetics and anti-angina medication. Living condition was reported as living alone or living with another person. This information was obtained from medical records and is therefore based on the medical history received directly from patients or indirectly; that is, from relatives or caregivers.

Only patients who were diagnosed with $\mathrm{AD}, \mathrm{VaD}, \mathrm{MixD}$, LBD, FTD and PDD were analyzed $(n=21,458)$. Patients attributed to unspecified dementia or to other types were not included in this study due to the imprecision of these diagnostic groups. Also, patients with the answer 'do not know' (8\%) about CV medication were excluded from this study. In total, 8,979 subjects were excluded from the whole SveDem population.

\section{Ethical issues}

Patients and their relatives were informed orally and in writing about SveDem and could decline participation. The study was approved by the regional ethical review board in Stockholm (Drn: 2013/147-31/2). The data were anonymized before statistical analysis. 


\section{Statistical analysis}

Descriptive data are presented as the mean and standard deviation. We checked the normality of distribution using the Kolmogorov-Smirnov test. In cases of continuous variables we used the independent sample $t$ test or one-way analysis of variance, and for categorical variables we used the chi-square test. Multivariate analysis was performed using binary logistic regression modeling to calculate odds ratios (ORs) with 95\% confidence intervals (CIs). Twotailed $P<0.05$ was considered to be statistically significant in all analytical procedures. Data were analyzed using the Statistical Package for the Social Sciences software version 22 (IBM Corporation, Armonk, NY, USA).

\section{Results}

A total of 19,743 incident dementia patients were included in this study. Their characteristics are presented in Table 1. There were 11,537 women (58\%) and 8,206 men (42\%). The mean age of the patients at the time of diagnosis was $78.9 \pm 7.8$ years and the mean MMSE score was $21 \pm 5$.

$\mathrm{AD}$ was the most common dementia disorder in the study population (41\%). MixD accounted for $27 \%$ and $\mathrm{VaD}$ for $25 \%$ of all dementia subtypes. Other types represented a minority (DLB, 3\%; FTD, 2\%; and PDD, 2\%). Patients diagnosed with MixD were the oldest (mean age $81.0 \pm 6.5$ years), while those with FTD represented the youngest group with a mean age of $70.0 \pm 10.0$ years.
The mean MMSE score varied between $21 \pm 5$ in the group of MixD and $24 \pm 5$ in FTD patients.

Figure 1 illustrates the distribution of various types of dementia in different age groups in the study population. The proportion of $\mathrm{VaD}$ ranged from 12 to $20.4 \%$ in different age groups and a gradual increase was observed from the youngest group ( $\leq 64$ years) to the group 85 to 89 years old. The rate of patients diagnosed with AD decreased steadily from $46.1 \%$ in the $\leq 64$ year group to $21.8 \%$ among those who were older than 90 years at the time of diagnosis. Moreover, as shown in Figure 1, the relative frequency of an unspecified type of dementia increased from $14.3 \%$ to as high as $36.6 \%$ in the oldest group. The proportion of patients diagnosed with $\mathrm{VaD}$ increased from $13.2 \%$ in 2007 to $20.1 \%$ in 2012 during the registration period (Figure 2). An opposite trend could be seen for the AD diagnosis, where the rate decreased from $42.7 \%$ to $26.8 \%$ from 2007 to 2012 .

Seventy percent of the population used CV drugs. These drugs were least common among $\mathrm{AD}$ patients $(59 \%)$ and most common among $\mathrm{VaD}$ patients (84\%). ChEIs were prescribed to $50 \%$ of patients and they were used most by $\mathrm{AD}$ patients (73\%) and least by FTD patients (7\%). On the other hand, NMDA antagonists were largely used in MixD $(17 \%)$ and only seldom in $\mathrm{VaD}(5 \%)$. The mean number of prescribed drugs ranged from $3.7 \pm 2.8$ in FTD patients to $6.5 \pm 3.2$ in PDD patients.

Table 1 Characteristics of the dementia patients, Swedish Dementia Registry 2007 to 2012

\begin{tabular}{|c|c|c|c|c|c|c|c|}
\hline & $\begin{array}{c}\text { Total } \\
(n=19,743)\end{array}$ & $\begin{array}{c}\text { AD } \\
(n=8,139 ; 41 \%)\end{array}$ & $\begin{array}{c}\text { MixD } \\
(n=5,203 ; 27 \%)\end{array}$ & $\begin{array}{c}\mathrm{VaD} \\
(n=4,982 ; 25 \%)\end{array}$ & $\begin{array}{c}\text { DLB } \\
(n=605 ; 3 \%)\end{array}$ & $\begin{array}{c}\text { FTD } \\
(n=409 ; 2 \%)\end{array}$ & $\begin{array}{c}\text { PDD } \\
(n=405 ; 2 \%)\end{array}$ \\
\hline \multicolumn{8}{|l|}{ Age } \\
\hline Mean & $78.9 \pm 7.8$ & $77.7 \pm 8.1$ & $81.0 \pm 6.5$ & $80.0 \pm 7.4$ & $76.5 \pm 7.1$ & $70.0 \pm 10.0$ & $75.2 \pm 7.0$ \\
\hline Range & 27 to 103 & 27 to 99 & 52 to 100 & 33 to 103 & 53 to 94 & 39 to 96 & 49 to 94 \\
\hline \multicolumn{8}{|l|}{ Gender, $n(\%)$} \\
\hline \multirow[t]{2}{*}{ Female } & 11,537 & 5,328 & 3,075 & 2,514 & 236 & 228 & 156 \\
\hline & (58.0\%) & (65.5\%) & (59.1\%) & $(50.5 \%)$ & (39.0\%) & $(55.7 \%)$ & (38.5\%) \\
\hline \multirow[t]{2}{*}{ Male } & 8,206 & 2,811 & 2,128 & 2,468 & 369 & 181 & 249 \\
\hline & (42.0\%) & (34.5\%) & (40.9\%) & (49.5\%) & (61.0\%) & (44.3\%) & $(61.5 \%)$ \\
\hline \multicolumn{8}{|l|}{ MMSE } \\
\hline Mean & $21.3 \pm 5.0$ & $21.6 \pm 5.0$ & $21.0 \pm 5.0$ & $21.2 \pm 4.9$ & $21.5 \pm 5.0$ & $23.6 \pm 5.0$ & $21.0 \pm 5.1$ \\
\hline Range & 0 to 30 & 0 to 30 & 0 to 30 & 0 to 30 & 0 to 30 & 3 to 30 & 6 to 30 \\
\hline Living alone (\%) & 44.3 & 43.0 & 48.7 & 45.7 & 34.7 & 33.0 & 22.7 \\
\hline CV drugs (\%) & 70.0 & 59.4 & 76.9 & 84.3 & 59.5 & 53.3 & 57.5 \\
\hline ChEls (\%) & 49.8 & 73.0 & 53.9 & 7.8 & 74.4 & 6.8 & 54.6 \\
\hline NMDA antagonists (\%) & 10.5 & 9.8 & 17.0 & 4.7 & 15.0 & 4.9 & 11.6 \\
\hline \multicolumn{8}{|l|}{ Number of drugs } \\
\hline Mean & $5.0 \pm 3.1$ & $4.0 \pm 2.8$ & $5.4 \pm 3.1$ & $6.2 \pm 3.2$ & $4.8 \pm 2.9$ & $3.7 \pm 2.8$ & $6.5 \pm 3.2$ \\
\hline Range & 0 to 24 & 0 to 21 & 0 to 24 & 0 to 23 & 0 to 17 & 0 to 13 & 0 to 19 \\
\hline
\end{tabular}

AD, Alzheimer's disease; ChEl, cholinesterase inhibitor; CV, cardiovascular; DLB, dementia with Lewy bodies; FTD, frontotemporal dementia; MixD, mixed dementia; MMSE, Mini Mental State Examination; NMDA, N-methyl-D-aspartate; PDD, Parkinson's disease dementia; VaD, vascular dementia. 


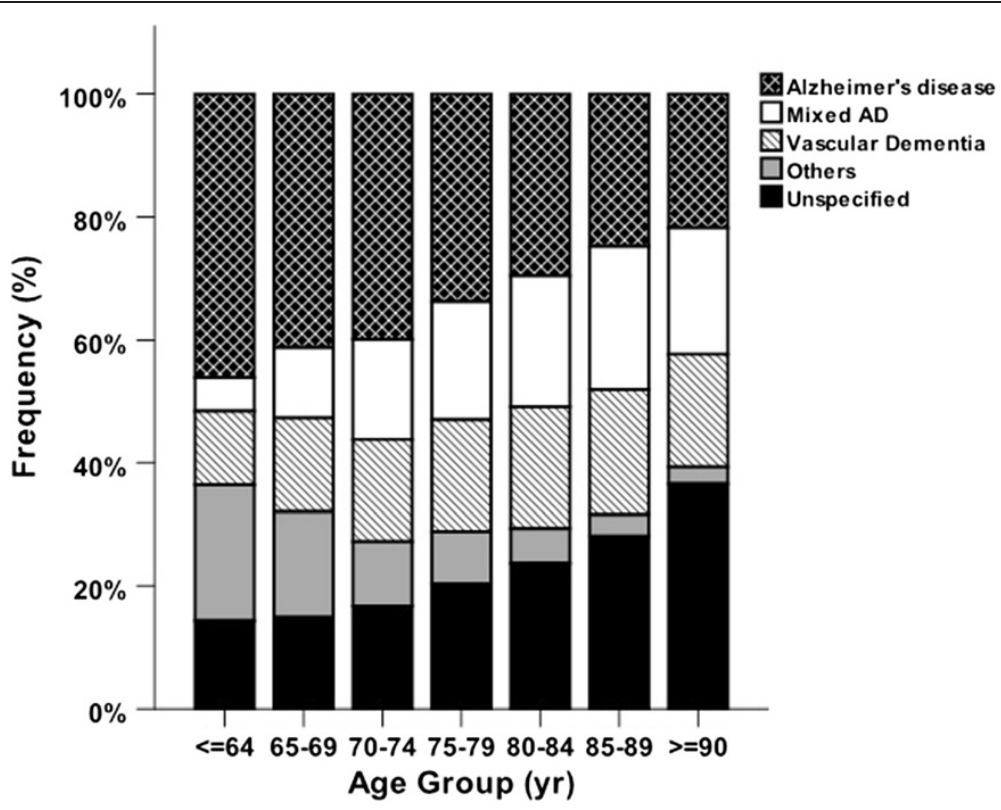

Figure 1 Proportion of various types of dementia in different age groups in patients registered in the Swedish Dementia Registry during 2007 to 2012. AD, Alzheimer's disease; yr, year.

Table 2 presents the differences between patients who used CV drugs and those who did not. Patients with CV medications were older and had a slightly higher MMSE score compared with those who were not treated with $\mathrm{CV}$ drugs. The use of ChEIs was higher among patients who did not receive $\mathrm{CV}$ medication, while the opposite was found for NMDA antagonists.

In the adjusted logistic regression analysis (Table 3) we found that male gender correlated with a higher probability of using $\mathrm{CV}$ medication when compared with women

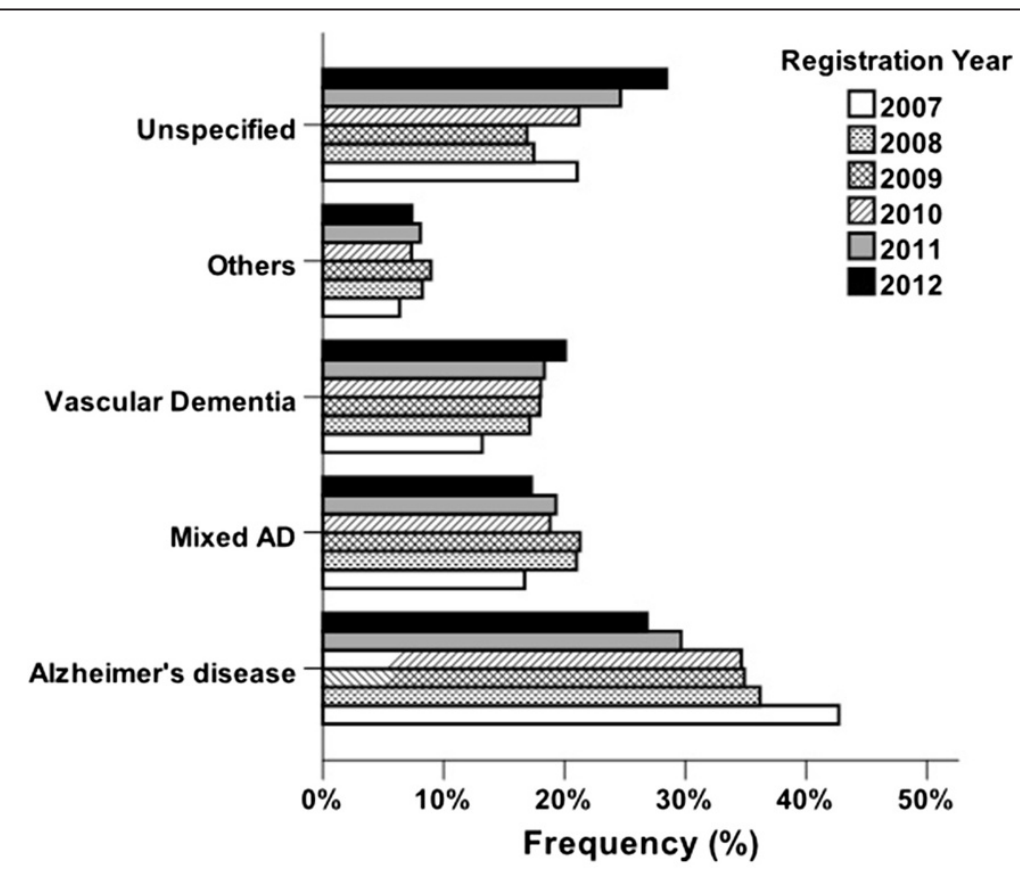

Figure 2 Frequency of different types of dementia in patients registered in the Swedish Dementia Registry during 2007 to 2012 within each registration year. $A D$, Alzheimer's disease. 
Table 2 Characteristics of patients with and without cardiovascular drugs, Swedish Dementia Registry 2007 to 2012

\begin{tabular}{|c|c|c|c|}
\hline & $\begin{array}{c}\text { CV medication } \\
(n=13,847)\end{array}$ & $\begin{array}{l}\text { Without CV medication } \\
\quad(n=5,896)\end{array}$ & $\begin{array}{c}P \\
\text { value }\end{array}$ \\
\hline \multicolumn{4}{|l|}{ Age } \\
\hline Mean & $79.6 \pm 7.2$ & $77.4 \pm 8.9$ & \multirow{2}{*}{$<0.001$} \\
\hline Range & 33 to 103 & 27 to 97 & \\
\hline \multicolumn{4}{|l|}{ Gender } \\
\hline Female (\%) & 55.9 & 64.4 & \multirow{2}{*}{$<0.001$} \\
\hline Male (\%) & 44.1 & 35.6 & \\
\hline \multicolumn{4}{|l|}{ MMSE } \\
\hline Mean & $21.4 \pm 4.9$ & $21.3 \pm 5.2$ & \multirow{2}{*}{$<0.001$} \\
\hline Range & 0 to 30 & 0 to 30 & \\
\hline Living alone (\%) & 43.7 & 45.7 & 0.006 \\
\hline ChEls (\%) & 46.1 & 58.5 & $<0.001$ \\
\hline NMDA antagonists (\%) & 10.6 & 10.3 & 0.028 \\
\hline \multicolumn{4}{|l|}{ Number of drugs } \\
\hline Mean & $5.8 \pm 3$ & $3,0 \pm 2.5$ & \multirow{2}{*}{$<0.001$} \\
\hline Range & 0 to 24 & 0 to 21 & \\
\hline AD (\%) & 34.9 & 56.0 & $<0.001$ \\
\hline MixD (\%) & 28.9 & 20.4 & $<0.001$ \\
\hline $\operatorname{VaD}(\%)$ & 30.3 & 13.2 & $<0.001$ \\
\hline DLB (\%) & 2.6 & 4.2 & $<0.001$ \\
\hline FTD (\%) & 1.6 & 3.2 & $<0.001$ \\
\hline PDD (\%) & 1.7 & 2.9 & $<0.001$ \\
\hline
\end{tabular}

$A D$, Alzheimer's disease; ChEl, cholinesterase inhibitor; CV, cardiovascular; DLB, dementia with Lewy bodies; FTD, frontotemporal dementia; MixD, mixed dementia; MMSE, Mini Mental State Examination; NMDA, N-methyl-D-aspartate; PDD, Parkinson's disease dementia; VaD, vascular dementia.

(adjusted OR $=1.45 ; 95 \% \mathrm{CI}=1.34$ to 1.57 ). Living alone was associated with lower use of CV drugs (adjusted $\mathrm{OR}=0.75,95 \% \mathrm{CI}=0.69$ to 0.81 ). Higher age and higher MMSE score were slightly related to the use of $\mathrm{CV}$ medication. There were no differences in the use of dementia medication between the patients with $\mathrm{CV}$ drugs and those without them. VaD showed the strongest association with use of CV drugs when compared with $\mathrm{AD}$ (adjusted $\mathrm{OR}=2.14 ; 95 \% \mathrm{CI}=1.89$ to 2.44 ). The probability of receiving $\mathrm{CV}$ medication was also significantly higher in MixD (adjusted OR $=1.57 ; 95 \% \mathrm{CI}=$ 1.43 to 1.73 ). DLB and PDD patients were less likely to receive $\mathrm{CV}$ medication, while the difference between FTD and AD was not significant.

\section{Discussion}

\section{Main findings}

In our study of 19,743 dementia patients, $\mathrm{AD}$ was the most common dementia disorder, followed by MixD and $\mathrm{VaD}$. DLB, FTD and PDD were less common. In the population of patients diagnosed with a dementia disorder, the overall
Table 3 Adjusted odds ratios for characteristics of patients with cardiovascular drugs compared to persons without cardiovascular medication, Swedish Dementia Registry 2007 to 2012

\begin{tabular}{ll}
\hline & Patients with CV medication $(\boldsymbol{n}=\mathbf{1 3 , 8 4 7})$ \\
\hline Age & $1.02(1.01 \text { to } 1.02)^{*}$ \\
Male gender & $1.45(1.34 \text { to } 1.57)^{*}$ \\
MMSE & $1.02(1.01 \text { to } 1.03)^{*}$ \\
Living alone & $0.75(0.69 \text { to } 0.81)^{*}$ \\
ChEls & $1.08(0.98$ to 1.19$)$ \\
NMDA antagonists & $0.98(0.85$ to 1.12$)$ \\
Total number of drugs & $1.53(1.50 \text { to } 1.56)^{*}$ \\
Dementia disorder & \\
$\quad$ AD & Reference \\
MixD & $1.57(1.43 \text { to } 1.73)^{*}$ \\
VaD & $2.14(1.89 \text { to } 2.44)^{*}$ \\
DLB & $0.71(0.58 \text { to } 0.87)^{*}$ \\
FTD & $0.91(0.71$ to 1.17$)$ \\
PDD & $0.31(0.24 \text { to } 0.40)^{*}$ \\
\hline
\end{tabular}

Age, MMSE and total number of drugs were analyzed as continuous variables. Odds ratios with $95 \%$ confidence interval adjusted for all variables in this table. AD, Alzheimer's disease; ChEl, cholinesterase inhibitor; $\mathrm{CV}$, cardiovascular; DLB, dementia with Lewy bodies; FTD, frontotemporal dementia; MixD, mixed dementia; MMSE, Mini Mental State Examination; NMDA, $N$-methyl-D-aspartate; PDD, Parkinson's disease dementia; VaD, vascular dementia. ${ }^{*}$ Statistically significant at the level of $P<0.001$

use of CV drugs was 70\%. Another study that investigated drug use in older persons in Sweden found that $66 \%$ of them used CV medication [47]. In a population-based study performed in Finland, the proportion of older persons who used CV medicines reached 86\% [48]. The prevalence of $\mathrm{CV}$ drugs was above $50 \%$ in all of the dementia disorders. As expected, $\mathrm{CV}$ drugs were the most common in patients diagnosed with $\mathrm{VaD}(84 \%)$ followed by MixD (77\%). However, the overall high use of CV medication in AD, DLB, FTD and PDD implies that these patients also suffer from $C V$ diseases to a great extent. Our finding that $\mathrm{AD}$ patients seemed to have comparably less CV comorbidities may be biased by the fact that dementia patients with $\mathrm{CV}$ comorbidities are more likely to be diagnosed with $\mathrm{VaD}$ or MixD than with AD. The relationship between $\mathrm{CV}$ diseases and $\mathrm{AD}$ is complex and may be influenced not only by $\mathrm{CV}$ medication, but also by anti-dementia medication such as ChEI. We have recently shown, using data from the SveDem registry, that treatment with ChEI in AD patients was associated with a reduced risk for myocardial infarction and death [49].

The burden of CV diseases in PDD is clinically relevant, especially in relation to treatment of Parkinson's disease. Some dopamine agonists are associated with a worse CV profile [50] and increased risk for heart valvular fibrosis $[51,52]$. We observed a very high total number of drugs in PDD patients $(6.5 \pm 3.2)$. This is consistent with previous 
research indicating that Parkinson's disease patients have a higher number of comorbidities compared with the general population [53]. However, PDD patients were significantly less likely to receive treatment with $\mathrm{CV}$ drugs when compared with AD patients. The DLB patients in our study population had a lower level of overall comorbidity. There is a lack of studies about the significance of CV diseases in DLB patients [54], but history of stroke has been reported to occur more often in DLB patients than in controls [55]. The relatively lower use of CV drugs in PDD and DLB patients compared with AD may be attributed to the fear of their side effects and difficulties in the management of blood pressure due to autonomic dysfunction [37].

Patients diagnosed with FTD represent the youngest group of dementia patients. They also seemed to have the least CV comorbidities, but after adjustment for age and other confounders they had a similar probability of receiving $\mathrm{CV}$ medication as $\mathrm{AD}$ patients (adjusted $\mathrm{OR}=0.91$; $95 \% \mathrm{CI}=0.71$ to 1.17 ). This confirms an already known relationship between advanced age and a higher amount of comorbidities [56].

One study has suggested that men suffering from dementia have a higher level of comorbidities [57]. Our investigation confirms this finding as male gender was associated with the use of CV drugs. However, this seems to be specific for $\mathrm{CV}$ medication, because older women use more medicines in general than older men [58-60]. Persons using CV drugs were found to have a lower probability of living alone, which could indicate that living alone would be associated with better $\mathrm{CV}$ health. However, people who live alone may not seek medical treatment or may have inadequate compliance with drug treatment. Indeed, it has been shown that living with another person is associated with increased adherence to medication [61]. There are gender differences regarding living conditions in older people. Older men are more likely to live at home while older women are more often institutionalized [62]. This could be explained by differences in social and marital conditions between older men and older women $[63,64]$ as well as by the fact that older women experience more disabilities compared with men [57]. In another investigation that compared medication in institutionalized and community-dwelling older people, institutionalization was found to be negatively associated with the use of many CV drugs [65].

\section{Strengths and limitations}

The findings of this study are strengthened by a large sample of patients from several parts of Sweden and different dementia subtypes. Compared with drug registrybased studies that use medicines prescribed to patients, our study may reflect the reality by having information about the drug treatment obtained directly from patients or their relatives. This study is cross-sectional; thus we cannot conclude any causal relationships. However, patients in SveDem are followed-up, which opens up possibilities for longitudinal studies in the future.

We did not include persons who were attributed to unspecified or other types of dementia $(n=7,264$; mean age $80.6 \pm 8.1$; mean MMSE $20.5 \pm 5.2$ ). Furthermore, in SveDem there is a possibility to respond with the answer 'do not know', which led to missing values for our data on $\mathrm{CV}$ medication and the necessity to exclude $8 \%$ of patients from the study. The persons excluded due to missing values differed from the study population in their mean age $(77.6 \pm 9.1$ vs. $78.9 \pm 7.8 ; P<0.001)$ and MMSE score $(21.0 \pm 5.8$ vs. $21.3 \pm 5.0 ; P<0.001)$, which could have introduced selection bias.

Patients at 58 memory clinics from all Sweden hospitals and from local to university hospitals were included. In the last year, the number of patients diagnosed in primary care units has significantly increased in SveDem and even more primary care units will be affiliated in the future. The reliability of the data in SveDem has been validated, especially in memory clinics. There is still a lower number of primary care units where the quality of registered data is monitored [43]. The data registered in memory clinics in a random sample of patients were in good agreement with medical records in a reliability test [66]. The validity of the diagnosis of dementia disorders has not been examined.

Considering the coverage of SveDem, our study could not provide incidence rates of dementia for the entire Swedish population. The incidence rate of dementia in Sweden is estimated to be about 24,000 new cases annually [67] and, considering the fact that nearly 8,000 newly diagnosed dementia patients are registered each year in SveDem, an overall coverage rate of $33 \%$ could be assumed. A recent study showed a prevalence rate of 17 to $18 \%$ in the Swedish population aged $>75$ years using data from two cohorts [68]. The study also concluded that the incidence of dementia might have decreased over the two recent decades. With regard to the frequency of various types of dementia within different age strata, our findings showed that the proportions of dementia patients diagnosed with $\mathrm{VaD}$ and unspecified dementia are increasing by age. Another previous report from Sweden claimed that $\mathrm{VaD}$ contributed to one-quarter of all dementias [69], which was found to be almost one-fifth or less in our study. However, in this previous survey there was no MixD included, which could have led to a higher incidence for $\mathrm{VaD}$. In line with this previous report [69], we also showed that the proportion of unspecified dementia was increasing among the older age groups. Furthermore, a steady increase was observed in the proportion of $\mathrm{VaD}$ in our study population over time during the 
registration period. Although this pattern could be seen in data from both primary care units and memory clinics, the simultaneous increase in the number of primary care units and older age of registered patients might have contributed to this increase in the proportion of $\mathrm{VaD}$ over time.

\section{Conclusion}

CV medication is used extensively across dementia disorders, and particularly in $\mathrm{VaD}$ and MixD. Future research should investigate the tolerability and effectiveness of these drugs in the different dementia disorders.

\section{Abbreviations \\ AD: Alzheimer's disease; ChEl: Cholinesterase inhibitor; Cl: Confidence interval; CV: Cardiovascular; DLB: Dementia with Lewy bodies; \\ FTD: Frontotemporal dementia; MixD: Mixed dementia; MMSE: Mini mental state examination; NMDA: N-methyl-D-aspartate; OR: Odds ratio; \\ PDD: Parkinson's disease dementia; SveDem: Swedish dementia registry; VaD: Vascular dementia.}

\section{Competing interests}

The authors declare that they have no competing interests.

\section{Authors' contributions}

PČ carried out the analysis, interpreted the results and wrote the manuscript. S-MF contributed to the statistical analysis and interpretation of the data. KJ participated in the design of the manuscript and contributed substantially to its content. BW participated in the coordination of the study and revised the manuscript critically for important intellectual content. ME conceived of the study, contributed to its design and drafting the manuscript. DR participated in the study design and its coordination. All authors approved the final version of the manuscript.

\section{Acknowledgements}

The authors are grateful to SveDem (www.svedem.se) for providing data for this study as well as many thanks to all participants in SveDem (patients, caregivers and staff). This study was supported financially by the Swedish Brain Power Network, the Swedish Association of Local Authorities and Regions, and Karolinska Institutet Foundations.

\section{Author details}

'Department of Neurobiology, Care Sciences and Society, Center for Alzheimer Research, Division for Neurogeriatrics, Karolinska Institutet, 14157 Huddinge, Sweden. 'International Clinical Research Center and St.Anne's University Hospital, Pekařská 53, 65691 Brno, Czech Republic. Department of Neurobiology, Care Sciences and Society, Center for Alzheimer Research, Division of Clinical Geriatrics, Karolinska Institutet, 14157 Huddinge, Sweden. ${ }^{4}$ Department of Neurobiology, Care Sciences and Society, Center for Alzheimer Research, Aging Research Center, Karolinska Institutet and Stockholm University, Gävlegatan 16, 11330 Stockholm, Sweden. ${ }^{5}$ Department of Geriatric Medicine, Karolinska University Hospital, 14186 Huddinge, Sweden.

Received: 3 February 2014 Accepted: 3 June 2014 Published: 16 June 2014

\section{References}

1. Kivipelto M, Helkala EL, Laakso MP, Hanninen T, Hallikainen M, Alhainen K, Soininen $\mathrm{H}$, Tuomilehto J, Nissinen A: Midlife vascular risk factors and Alzheimer's disease in later life: longitudinal, population based study. Bmj 2001, 322:1447-1451.

2. Kivipelto M, Ngandu T, Fratiglioni L, Viitanen M, Kareholt I, Winblad B, Helkala EL, Tuomilehto J, Soininen H, Nissinen A: Obesity and vascular risk factors at midlife and the risk of dementia and Alzheimer disease. Arch Neurol 2005, 62:1556-1560.

3. Kivipelto M, Laakso MP, Tuomilehto J, Nissinen A, Soininen H: Hypertension and hypercholesterolaemia as risk factors for Alzheimer's disease: potential for pharmacological intervention. CNS drugs 2002, 16:435-444.
4. Ott A, Breteler MM, de Bruyne MC, van Harskamp F, Grobbee DE, Hofman A: Atrial fibrillation and dementia in a population-based study. The Rotterdam Study. Stroke J Cerebr Circ 1997, 28:316-321.

5. Qiu C, Winblad B, Marengoni A, Klarin I, Fastbom J, Fratiglioni L: Heart failure and risk of dementia and Alzheimer disease: a population-based cohort study. Arch Intern Med 2006, 166:1003-1008.

6. Soto ME, van Kan GA, Nourhashemi F, Gillette-Guyonnet S, Cesari M, Cantet $C$, Rolland Y, Vellas B: Angiotensin-converting enzyme inhibitors and Alzheimer's disease progression in older adults: results from the Reseau sur la Maladie d'Alzheimer Francais cohort. J Am Geriatr Soc 2013, 61:1482-1488.

7. Yasar S, Xia J, Yao W, Furberg CD, Xue QL, Mercado Cl, Fitzpatrick AL, Fried LP, Kawas CH, Sink KM, Williamson JD, DeKosky ST, Carlson MC, Ginkgo Evaluation of Memory (GEM) Studylnvestigators: Antihypertensive drugs decrease risk of Alzheimer disease: Ginkgo Evaluation of Memory Study. Neurology 2013, 81:896-903.

8. Kennelly SP, Abdullah L, Paris D, Parish J, Mathura V, Mullan M, Crawford F, Lawlor BA, Kenny RA: Demonstration of safety in Alzheimer's patients for intervention with an anti-hypertensive drug Nilvadipine: results from a 6-week open label study. Int J Geriatr Psychiat 2011, 26:1038-1045.

9. Khachaturian AS, Zandi PP, Lyketsos CG, Hayden KM, Skoog I, Norton MC, Tschanz JT, Mayer LS, Welsh-Bohmer KA, Breitner JC: Antihypertensive medication use and incident Alzheimer disease: the Cache County Study. Arch Neurol 2006, 63:686-692.

10. Gelber RP, Ross GW, Petrovitch H, Masaki KH, Launer L, White LR: Antihypertensive medication use and risk of cognitive impairment: the Honolulu-Asia Aging Study. Neurology 2013, 81:888-895.

11. Anekonda TS, Quinn JF, Harris C, Frahler K, Wadsworth TL, Woltjer RL: L-type voltage-gated calcium channel blockade with isradipine as a therapeutic strategy for Alzheimer's disease. Neurobiol Dis 2011, 41:62-70.

12. Popovic M, Caballero-Bleda M, Popovic N, Bokonjic D, Dobric S: Neuroprotective effect of chronic verapamil treatment on cognitive and noncognitive deficits in an experimental Alzheimer's disease in rats. Int J Neurosci 1997, 92:79-93.

13. Agostini JV, Tinetti ME, Han L, McAvay G, Foody JM, Concato J: Effects of statin use on muscle strength, cognition, and depressive symptoms in older adults. J Am Geriatr Soc 2007, 55:420-425.

14. Forette F, Seux ML, Staessen JA, Thijs L, Birkenhager WH, Babarskiene MR, Babeanu S, Bossini A, Gil-Extremera B, Girerd X, Laks T, Lilov E, Moisseyev V Tuomilehto J, Vanhanen H, Webster J, Yodfat Y, Fagard R: Prevention of dementia in randomised double-blind placebo-controlled Systolic Hypertension in Europe (Syst-Eur) trial. Lancet 1998, 352:1347-1351.

15. Lithell H, Hansson L, Skoog I, Elmfeldt D, Hofman A, Olofsson B, Trenkwalder P, Zanchetti A, SCOPE Study Group: The Study on Cognition and Prognosis in the Elderly (SCOPE): principal results of a randomized double-blind intervention trial. J Hypertens 2003, 21:875-886.

16. Wright JW, Harding JW: The brain renin-angiotensin system: a diversity of functions and implications for CNS diseases. Pflugers Archiv Eur J Physiol 2013, 465:133-151

17. Ashby EL, Kehoe PG: Current status of renin-aldosterone angiotensin system-targeting anti-hypertensive drugs as therapeutic options for Alzheimer's disease. Expert Opin Invest Drugs 2013, 22:1229-1242.

18. Bay-Richter C, Hallberg L, Ventorp F, Janelidze S, Brundin L: Aldosterone synergizes with peripheral inflammation to induce brain IL-1 $\beta$ expression and depressive-like effects. Cytokine 2012, 60:749-754.

19. Dong YF, Kataoka K, Tokutomi Y, Nako H, Nakamura T, Toyama K, Sueta D, Koibuchi N, Yamamoto E, Ogawa H, Kim-Mitsuyama S: Perindopril, a centrally active angiotensin-converting enzyme inhibitor, prevents cognitive impairment in mouse models of Alzheimer's disease. FASEB J Official Public Feder Am Soc Exp Biol 2011, 25:2911-2920.

20. Yamada K, Uchida S, Takahashi S, Takayama M, Nagata Y, Suzuki N, Shirakura S, Kanda T: Effect of a centrally active angiotensin-converting enzyme inhibitor, perindopril, on cognitive performance in a mouse model of Alzheimer's disease. Brain Res 2010, 1352:176-186.

21. O'Caoimh R, Healy L, Gao Y, Svendrovski A, Kerins DM, Eustace J, Kehoe PG, Guyatt G, Molloy DW: Effects of centrally acting angiotensin converting enzyme inhibitors on functional decline in patients with alzheimer's disease. J Alzheimers Dis 2014, 40:595-603.

22. Li NC, Lee A, Whitmer RA, Kivipelto M, Lawler E, Kazis LE, Wolozin B: Use of angiotensin receptor blockers and risk of dementia in a predominantly male population: prospective cohort analysis. BMJ 2010, 340:b5465. 
23. Zhou B, Teramukai S, Fukushima M: Prevention and treatment of dementia or Alzheimer's disease by statins: a meta-analysis. Dement Geriatr Cogn Disord 2007, 23:194-201.

24. Brunnstrom H, Gustafson L, Passant U, Englund E: Prevalence of dementia subtypes: a 30-year retrospective survey of neuropathological reports. Arch Gerontol Geriatr 2009, 49:146-149.

25. Rockwood K, Macknight C, Wentzel C, Black S, Bouchard R, Gauthier S, Feldman $\mathrm{H}$, Hogan D, Kertesz A, Montgomery P: The diagnosis of 'mixed' dementia in the Consortium for the Investigation of Vascular Impairment of Cognition (CIVIC). Ann NY Acad Sci 2000, 903:522-528.

26. Rahkonen T, Eloniemi-Sulkava U, Rissanen S, Vatanen A, Viramo P, Sulkava R: Dementia with Lewy bodies according to the consensus criteria in a general population aged 75 years or older. J Neurol Neurosurg Psychiatry 2003, 74:720-724.

27. Zaccai J, McCracken C, Brayne C: A systematic review of prevalence and incidence studies of dementia with Lewy bodies. Age Ageing 2005, 34:561-566.

28. McKeith IG, Dickson DW, Lowe J, Emre M, O'Brien JT, Feldman H, Cummings J, Duda JE, Lippa C, Perry EK, Aarsland D, Arai H, Ballard CG, Boeve B, Burn DJ, Costa D, Del Ser T, Dubois B, Galasko D, Gauthier S, Goetz CG, Gomez-Tortosa E, Halliday G, Hansen LA, Hardy J, Iwatsubo T, Kalaria RN, Kaufer D, Kenny RA, Korczyn A, et al: Diagnosis and management of dementia with Lewy bodies: third report of the DLB Consortium. Neurology 2005, 65:1863-1872.

29. Imfeld P, Brauchli Pernus YB, Jick SS, Meier CR: Epidemiology, co-morbidities, and medication use of patients with Alzheimer's disease or vascular dementia in the UK. JAD 2013, 35:565-573.

30. Holstein J, Chatellier G, Piette F, Moulias R: Prevalence of associated diseases in different types of dementia among elderly institutionalized patients: analysis of 3447 records. J Am Geriatr Soc 1994, 42:972-977.

31. Sanderson M, Wang J, Davis DR, Lane MJ, Cornman CB, Fadden MK: Co-morbidity associated with dementia. Am J Alzheimers Dis Other Dement 2002, 17:73-78.

32. Hill JW, Futterman R, Duttagupta S, Mastey V, Lloyd JR, Fillit H: Alzheimer's disease and related dementias increase costs of comorbidities in managed Medicare. Neurology 2002, 58:62-70.

33. Eaker ED, Mickel SF, Chyou PH, Mueller-Rizner NJ, Slusser JP: Alzheimer's disease or other dementia and medical care utilization. Ann Epidemiol 2002, 12:39-45.

34. Fereshtehnejad SM, Jonhell K, Eriksdotter M: Anti-dementia drugs and co-medication amongst patients with alzheimer's disease: Investigating real-world drug use in clinical practice using the Swedish dementia quality registry (SveDem). Drugs Aging 2014, 2014:2014.

35. Allan LM, Ballard CG, Allen J, Murray A, Davidson AW, McKeith IG, Kenny RA: Autonomic dysfunction in dementia. J Neurol Neurosurg Psychiatry 2007, 78:671-677.

36. Robles Bayon A, Gude Sampedro F, Torregrosa Quesada JM: Bradycardia in frontotemporal dementia. Neurologia 2014, 29:76-85.

37. Postuma RB, Gagnon JF, Pelletier A, Montplaisir J: Prodromal autonomic symptoms and signs in Parkinson's disease and dementia with Lewy bodies. Mov. Disord Official J Mov Disord Soc 2013, 28:597-604.

38. Affoo RH, Foley N, Rosenbek J, Kevin Shoemaker J, Martin RE: Swallowing dysfunction and autonomic nervous system dysfunction in alzheimer's disease: a scoping review of the evidence. J Am Geriatr Soc 2013, 61:2203-2213.

39. Fiss T, Thyrian JR, Wucherer D, Assmann G, Kilimann I, Teipel SJ, Hoffmann $W$ : Medication management for people with dementia in primary care: description of implementation in the DelpHi study. BMC Geriatr 2013, 13:121.

40. Arlt S, Lindner R, Rosler A, von Renteln-Kruse W: Adherence to medication in patients with dementia: predictors and strategies for improvement. Drugs Aging 2008, 25:1033-1047.

41. Alladi S, Mekala S, Chadalawada SK, Jala S, Mridula R, Kaul S: Subtypes of dementia: a study from a memory clinic in India. Dement Geriatr Cogn Dis 2011, 32:32-38.

42. Johnell K, Religa D, Eriksdotter M: Differences in drug therapy between dementia disorders in the Swedish dementia registry: a nationwide study of over 7,000 patients. Dement Geriatr Cogn Dis 2013, 35:239-248

43. Årsrapport SveDem 2012. [http://www.ucr.uu.se/svedem/index.php/ om-svedem/arsrapporter]
44. World Health Organization: The ICD-10 Classification of Mental and Behavioural Disorders. Diagnostic Criteria for Research. Geneva: WHO; 1993.

45. Clinical and neuropathological criteria for frontotemporal dementia. The Lund and Manchester Groups. I Neurol Neurosurg Psychiatry 1994 57:416-418

46. Schneeweiss S, Seeger JD, Maclure M, Wang PS, Avorn J, Glynn RJ: Performance of comorbidity scores to control for confounding in epidemiologic studies using claims data. Am J Epidemiol 2001, 154:854-864.

47. Johnell K, Fastbom J: The association between use of cardiovascular drugs and antidepressants: a nationwide register-based study. Eur J Clin Pharmacol 2008, 64:1119-1124.

48. Jyrkka J, Vartiainen L, Hartikainen S, Sulkava R, Enlund H: Increasing use of medicines in elderly persons: a five-year follow-up of the Kuopio 75+ Study. Eur J Clin Pharmacol 2006, 62:151-158.

49. Nordstrom P, Religa D, Wimo A, Winblad B, Eriksdotter M: The use of cholinesterase inhibitors and the risk of myocardial infarction and death: a nationwide cohort study in subjects with Alzheimer's disease. Eur Heart J 2013, 34:2585-2591.

50. Trifiro G, Morgante L, Tari M, Arcoraci V, Savica R: Burden of cardiovascular diseases in elderly with Parkinson's disease who start a dopamine agonist agent. J Am Geriatr Soc 2008, 56:371-373.

51. Schade R, Andersohn F, Suissa S, Haverkamp W, Garbe E: Dopamine agonists and the risk of cardiac-valve regurgitation. N Eng J Med 2007, 356:29-38.

52. Zanettini R, Antonini A, Gatto G, Gentile R, Tesei S, Pezzoli G: Valvular heart disease and the use of dopamine agonists for Parkinson's disease. N Eng J Med 2007, 356:39-46.

53. Lethbridge L, Johnston GM, Turnbull G: Co-morbidities of persons dying of Parkinson's disease. Prog Palliat Care 2013, 21:140-145.

54. Magierski R, Kloszewska I, Sobow TM: The influence of vascular risk factors on the survival rate of patients with dementia with Lewy bodies and Alzheimer disease. Neurol Neurochir Pol 2010, 44:139-147.

55. Boot BP, Orr CF, Ahlskog JE, Ferman TJ, Roberts R, Pankratz VS, Dickson DW, Parisi J, Aakre JA, Geda YE, Knopman DS, Petersen RC, Boeve BF: Risk factors for dementia with Lewy bodies: a case-control study. Neurology 2013, 81:833-840.

56. Boyd CM, Darer J, Boult C, Fried LP, Boult L, Wu AW: Clinical practice guidelines and quality of care for older patients with multiple comorbid diseases: implications for pay for performance. JAMA 2005, 294:716-724.

57. Sinforiani E, Citterio A, Zucchella C, Bono G, Corbetta S, Merlo P, Mauri M: Impact of gender differences on the outcome of Alzheimer's disease. Dement Geriatr Cogn Dis 2010, 30:147-154.

58. Kennerfalk A, Ruigomez A, Wallander MA, Wilhelmsen L, Johansson S: Geriatric drug therapy and healthcare utilization in the United kingdom. Ann Pharmacother 2002, 36:797-803.

59. Pitkala $\mathrm{KH}$, Strandberg TE, Tilvis RS: Inappropriate drug prescribing in home-dwelling, elderly patients: a population-based survey. Arch Int Med 2002, 162:1707-1712.

60. Johnell K, Weitoft GR, Fastbom J: Sex differences in inappropriate drug use: a register-based study of over 600,000 older people. Ann Pharmacother 2009, 43:1233-1238.

61. Barat I, Andreasen F, Damsgaard EM: Drug therapy in the elderly: what doctors believe and patients actually do. Br J Clin Pharmacol 2001, 51:615-622.

62. Wastesson JW, Parker MG, Fastbom J, Thorslund M, Johnell K: Drug use in centenarians compared with nonagenarians and octogenarians in Sweden: a nationwide register-based study. Age Ageing 2012, 41:218-224.

63. Pezzin LE, Pollak RA, Schone BS: Complex families and late-life outcomes among elderly persons: disability, institutionalization, and longevity. J. Marriage Fam 2013, 75:1084-1097.

64. Duane F, Brasher K, Koch S: Living alone with dementia. Dementia (London) 2013, 12:123-136

65. Johnell K, Fastbom J: Comparison of prescription drug use between community-dwelling and institutionalized elderly in Sweden. Drugs Aging 2012, 29:751-758.

66. Årsrapport SveDem 2010. [http://www.ucr.uu.se/svedem/index.php/ om-svedem/arsrapporter]

67. Skoldunger A, Wimo A, Johnell K: Net costs of dementia in Sweden - an incidence based 10 year simulation study. Int J Geriatr Psychiatry 2012, 27:1112-1117 
68. Qiu C, von Strauss E, Backman L, Winblad B, Fratiglioni L: Twenty-year changes in dementia occurrence suggest decreasing incidence in central Stockholm, Sweden. Neurology 2013, 80:1888-1894.

69. Fratiglioni L, Grut M, Forsell Y, Viitanen M, Grafstrom M, Holmen K, Ericsson K, Backman L, Ahlbom A, Winblad B: Prevalence of Alzheimer's disease and other dementias in an elderly urban population: relationship with age, sex, and education. Neurology 1991, 41:1886-1892.

doi:10.1186/alzrt264

Cite this article as: Cermakova et al:: Cardiovascular medication burden in dementia disorders: a nationwide study of 19,743 dementia patients in the Swedish Dementia Registry. Alzheimer's Research \& Therapy

2014 6:34.

\section{Submit your next manuscript to BioMed Central and take full advantage of:}

- Convenient online submission

- Thorough peer review

- No space constraints or color figure charges

- Immediate publication on acceptance

- Inclusion in PubMed, CAS, Scopus and Google Scholar

- Research which is freely available for redistribution 